https://doi.org/10.15407/dopovidi2021.04.086

УДК 616.998.7:578.834.1

\title{
C.В. Межжерін
}

\section{I.I. Козиненко}

В.М. Титар, https://orcid.org/0000-0002-0864-2548

Інститут зоології ім. І.І. Шмальгаузена НАН України, Київ

E-mail: s.mezhzherin@gmail.com

\section{Біокліматичні фактори і перебіг пандемії COVID-19 в Свропі: місце України}

\author{
Представлено членом-кореспондентом НАН України С.О. Афанасьєвим
}

Залежнісь перебігу пандемії COVID-19 від 8335 проаналізованих біокліматичних факторів доведена в масштабах Європи. Їхня комбінація об'єктивно визначає просторовий базис розвитку пандемії. Оптимальні умови для розвитку пандемії визначаються двома ключовими параметрами: мінімальною температурою найхолоднішого тижня року в межах від 6 до $10^{\circ} \mathrm{C}$ і сталим рівнем сезонної вологості. Найбільш придатними для розвитку пандемії є території країн Західної Европи (показники придатності від 60 до 80 \%). Центральна і Північна Європа характеризуються середнім рівнем придатності (50-60%). Найменший рівень в Східній Свропі близько 50 \%. Територія Украйни належить до середньо придатних, а отже, з урахуванням незначної, як для більшості європейських країн, щільності населення, будь-які ексцесивні прояви пандемії мають бути пояснені лише низькою ефективністю медико-організаційних заходів у масштабі країни.

Ключові слова: COVID-19, клімат, моделювання екологічної ніші, Європа, Украӥна.

Коронавірусна хвороба (COVID-19) вперше виявлена у людини в грудні 2019 р. в місті Ухань, Центральний Китай. Епідемічний процес, спричинений коронавірусом SARS-CoV-2, розпочався як спалах, що розвинувся у пандемію, яка охопила майже весь світ. При цьому характер пандемії та масовість захворювань на перший погляд мають визначені географічні особливості, які загалом збігаються з біокліматичним районуванням Земної кулі. Крім того, інвазивні процеси в Свразіі мають чітку спрямованість, що відповідає “Великому євразійському міграційному шляху”, переміщення по якому зі сходу на захід, очевидно, підтримується певними біокліматичними особливостями Західної та Східної Палеарктик [1]. Виходячи з цих обставин, а також з того, що COVID-19, як і більшість респіраторних захворювань, має сезонну активність, цілком адекватним є припущення про певну залежність перебігу пандемії від біокліматичних обставин. Проте, на думку учасників міжнародного

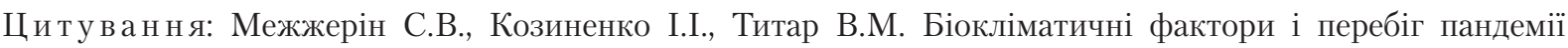
COVID-19 в Європі: місце України. Допов. Нащ. акад. наук Укр. 2021. № 4. С. 86-93. https://doi.org/10.15407/ dopovidi2021.04.086 
симпозіуму з питань ролі кліматологічних, метеорологічних та екологічних факторів у виникненні пандемії COVID-19, що відбувся під егідою Всесвітньої метеорологічної організації, умови навколишнього середовища не стали основною рушійною силою початкового етапу перебігу пандемії (https://community.wmo.int/). У Всесвітній організації охорони здоров’я (BОО3) також вважають (https://www.who.int/), що поки немає переконливих доказів того, що біокліматичні фактори мають істотний вплив на передачу інфекції. Тоді як добре відомо, що погодно-кліматичні і абіотичні екологічні чинники (температура, вологість, якість повітря і ультрафіолетове світло) впливають на поширення респіраторних вірусів. Стосовно коронавірусної пандемії інтерес до цього питання намітився останнім часом [2]. Дослідження, проведені як в окремих країнах [3-5], так і в більш глобальному масштабі [6-8], показали, що біокліматичні фактори мають певний вплив на перебіг пандеміі. Слід припустити, що навколишнє середовище виступає модулятором передачі SARS-CoV-2 від людини до людини і несприятливі для вірусу умови спричинюють більш швидку дестабілізацію вірусу поза організмом людини [10, 11].

Отже, роль кліматичних чинників у поширенні пандемії COVID-19 досі залишається багато в чому невизначеною. 3 появою нових гео- і біоінформаційних технологій з'явилася можливість моделювати географічне поширення організмів чи інших біологіних об'єктів на основі їхніх зв'язків з біокліматичними умовами навколишнього середовища [11]. Це так званий кореляційний підхід, за допомогою якого можна з'ясувати комплекс умов, завдяки яким популяції можуть успішно існувати. При цьому простір, де такі умови складаються саме в такий комплекс, розглядається як модель їхнього ареалу.

Методи просторового екологічного моделювання зараз широко використовуються в різних галузях біології та географії: для оцінки біологічного різноманіття територій, здатності видів до розселення (в тому числі шкідників та патогенів), а також для з'ясування особливостей їх екологічних ніш. Досі такого роду біогеографічні моделі головним чином застосовували до багатоклітинних організмів, проте останнім часом зросла кількість досліджень еколого-географічних зв’язків між поширенням патогенних бактерій і вірусів 3 цілою низкою біотичних та абіотичних факторів навколишнього середовища [10, 11], що зумовлено необхідністю прогнозування поширення патогенів і розвитку пандемій.

Отже, метою дослідження стало створення моделі географічного поширення коронавірусу SARS-CoV-2 в Свропі з акцентом на територію України. Для цього використовується екологічне моделювання ареалу пандемії в Свропі на підставі біокліматичних показників, з подальшим з'ясуванням кореляції між прогнозованою моделлю придатності клімату для коронавірусу з реальними показниками захворюваності в місцях її реєстрації. Якщо цей зв’язок існує, то виникає можливість встановити, наскільки територія України є з точки зору біокліматичних факторів придатною для поширення коронавірусу і, відповідно, розвитку пандемї.

Для просторового моделювання необхідна інформація про поширення організмів у вигляді точкових реєстрацій з прив'язкою до географічних координат. Джерелом таких даних був вільний для завантаження геокодований реєстр з репозиторію, який веде Центр системних наук та інженерії при Університеті Джона Гопкінса за підтримки ESRI Living Atlas Team (https://github.com/CSSEGISandData/COVID-19 та https://coronavirusresources.esri.com). Зокрема, були завантажені кумулятивні дані, які відображають ситуа- 


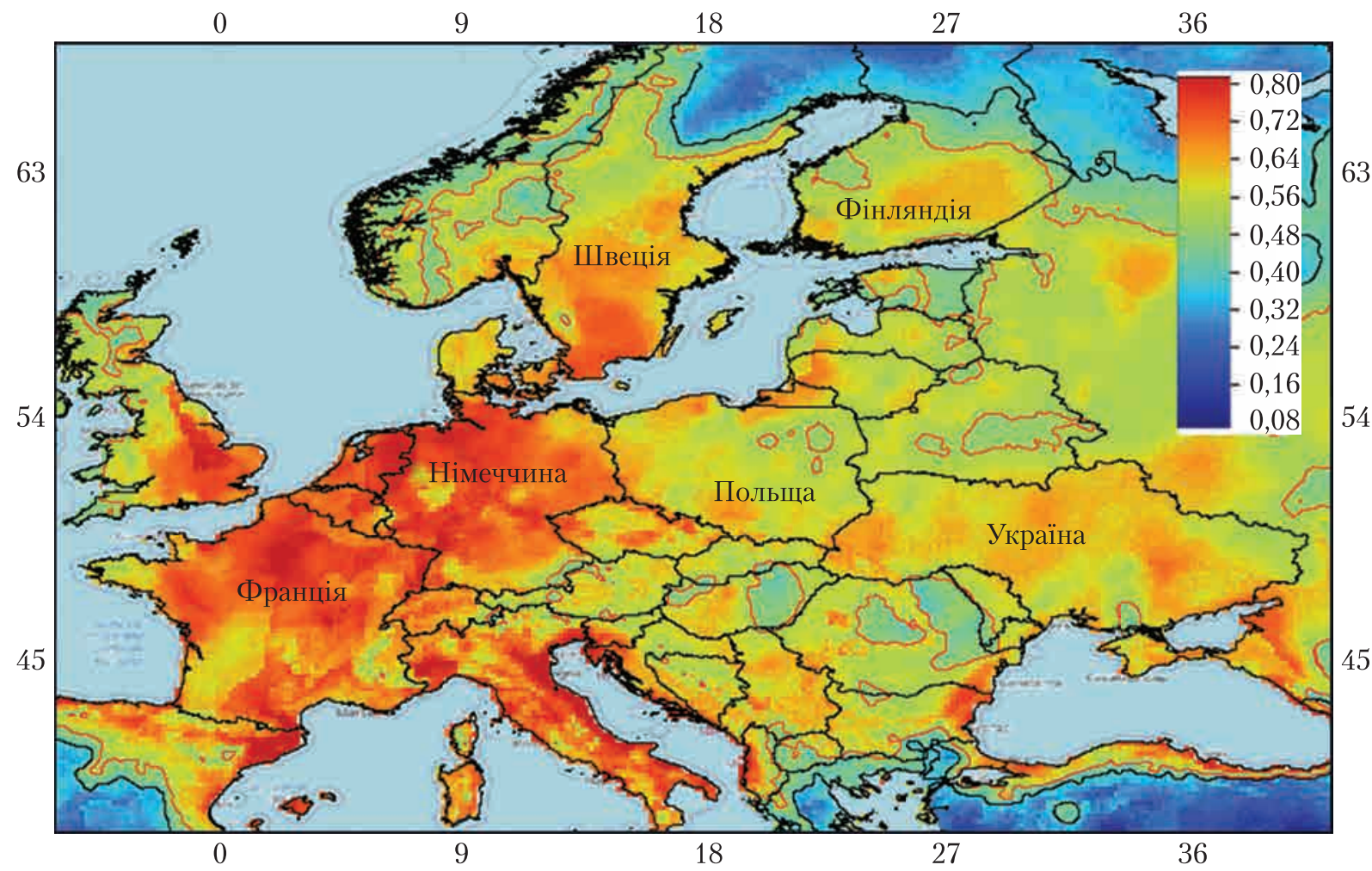

Puc. 1. ГIC-модель поширення COVID-19 в Свропі. Кліматична придатність територій для SARS-CoV-2 позначена в легенді градієнтом кольорів (червоний - найбільш придатні, синій - найменш). Чорна контурна лінія позначає 10-процентильний поріг, червона - межу між територіями, де кліматична придатність територій для вірусу перевищує чи є меншою за 50 \%

цію з COVID-19 у світі станом на 6 березня 2021 р. Крім даних стосовно географічних координат місць, де зареєстрована хвороба, в базах наведені кількості підтверджених захворювань, одужань та смертей, а також нормований показник, представлений кількістю підтверджених захворювань на 100 тис. населення. Оскільки показники кількості підтверджених захворювань, одужань та смертей залежать від чисельності населення в місцях, де реєструвалася хвороба, до уваги взятий лише показник кількості підтверджених захворювань на 100 тис. населення. В ГІС-платформі SAGA GIS [12] ці дані були трансформовані у векторний формат (шейп-файл) та доведені до меж Європи. Таким чином отримано 226 точкових реєстрацій для побудови відповідної комп'ютерної моделі.

У дослідженні використаний метод машинного навчання, що базується на баєсових адитивних деревах регресії (BART), і реалізований в програмному середовищі R (пакет “embarcadero” [13]). При цьому продукується прив’язана до географічних координат карта поширення прогнозних значень придатності середовища існування, які змінюються в межах від 0 до 100 \%. Оскільки як предиктори беруться кліматичні показники, то на цій карті має бути видно, де для SARS-CoV-2 передбачається, що клімат буде придатний, а де навпаки. Якість моделі оцінювали, використовуючи ROC-аналіз [10]. Кількісну інтерпретацію ROC дає показник AUC - площа, обмежена ROC-кривою і віссю частки помилкових 
позитивних класифікацій. Чим вищий показник AUC, тим якісніший класифікатор. Моделі зі значенням AUC вище 0,7 вважаються прийнятними. Програма BART автоматично визначає внесок кожного предиктора в побудову кінцевої моделі та, крім того, будує криві залежності, які описують зміни прогнозних значень придатності середовища в градієнті окремих предикторів.

Для цілей моделювання вибрана база CliMond [14]. Вона містить біокліматичні індекси, що враховують температуру і вологість, а також показники сонячної радіації. Всього задіяно 35 параметрів, що характеризують сучасний клімат.

Дослідження зв'язку між прогнозованою моделлю придатності клімату для SARS-CoV-2, який представлений у растровому форматі з реальними показниками коронавірусної хвороби в місцях її реєстрації здійснене для прив’язки значень цього растра до шейп-файла за модулем SAGA GIS. Таким чином, до інформації про поширення COVID-19 та відповідних епідеміологічних показників додана інформація про кліматичну нішу вірусу, зв'язки між якими можна дослідити методами лінійної регресії [15].

Моделювання потенційного поширення COVID-19 на підставі біокліматичних факторів показало, що хвороба має охоплювати майже всю територію Свропи (рис. 1). При цьому показник AUC становить 0,80, тобто модель поширення добре узгоджується з емпіричними даними та задовільно їх описує.

На більшій частині Західної Свропи (у Північній Іспанії, Італії, Франції, Німеччині та Південній Англії), де значного розвитку набула коронавірусна хвороба, клімат є особливо сприятливим для SARS-CoV-2. Про це свідчить показник біокліматичної придатності на рівні 70-80\%. Значно менші значення в Північній і Центральній Європі. В цих регіонах максимальну придатність має територія Швеції, де вона перевищує 60 \%. У Норвегії та Фінляндії не тільки менші площі високої придатності, але й максимальні показники становлять лише 53 та 38 \% відповідно. Отже, у Швеції COVID-19 досяг найбільшого спалаху серед Скандинавських країн, що можна пояснити особливостями медико-організаційних підходів. Проте можливо, що в цій ситуації свою роль зіграв біокліматичний чинник. Те саме можна сказати, порівнюючи сусідні Чеську Республіку та Словаччину, де рівень придатності територій до COVID-19 різний і не перевищує 60 \%. Стосовно країн Східної

Результати регресійного аналізу зв'язку між кліматичною придатністю території для SARS-CoV-2 та кумулятивним показником кількості підтверджених захворювань на 100 тис. населення

\begin{tabular}{|c|c|c|c|c|c|}
\hline $\begin{array}{c}\text { Коефіцієнт } \\
\text { лінійної регресії } \\
y(x)=b+a \cdot x\end{array}$ & $\begin{array}{c}\text { Обчислене } \\
\text { значення }\end{array}$ & $\begin{array}{c}\text { Стандартна } \\
\text { похибка (S.E.) }\end{array}$ & $\begin{array}{c}\text { Коефіцієнт } \\
\text { кореляції }(r) \\
\text { Пірсона }\end{array}$ & $\begin{array}{l}t \text { критерій } \\
\text { Стьюдента }\end{array}$ & $p$ \\
\hline \multicolumn{6}{|c|}{ Свропа } \\
\hline$a$ & 21750 & 1429,3 & \multirow[t]{2}{*}{0,2236} & \multirow[t]{2}{*}{3,40} & \multirow[t]{2}{*}{0,0007} \\
\hline$b$ & 10240 & 233120 & & & \\
\hline \multicolumn{6}{|c|}{ Україна } \\
\hline$a$ & 28,934 & 5,5268 & \multirow[t]{2}{*}{0,4010} & \multirow[t]{2}{*}{2,099} & \multirow[t]{2}{*}{0,0470} \\
\hline$b$ & $-5,8753$ & 6,7684 & & & \\
\hline
\end{tabular}



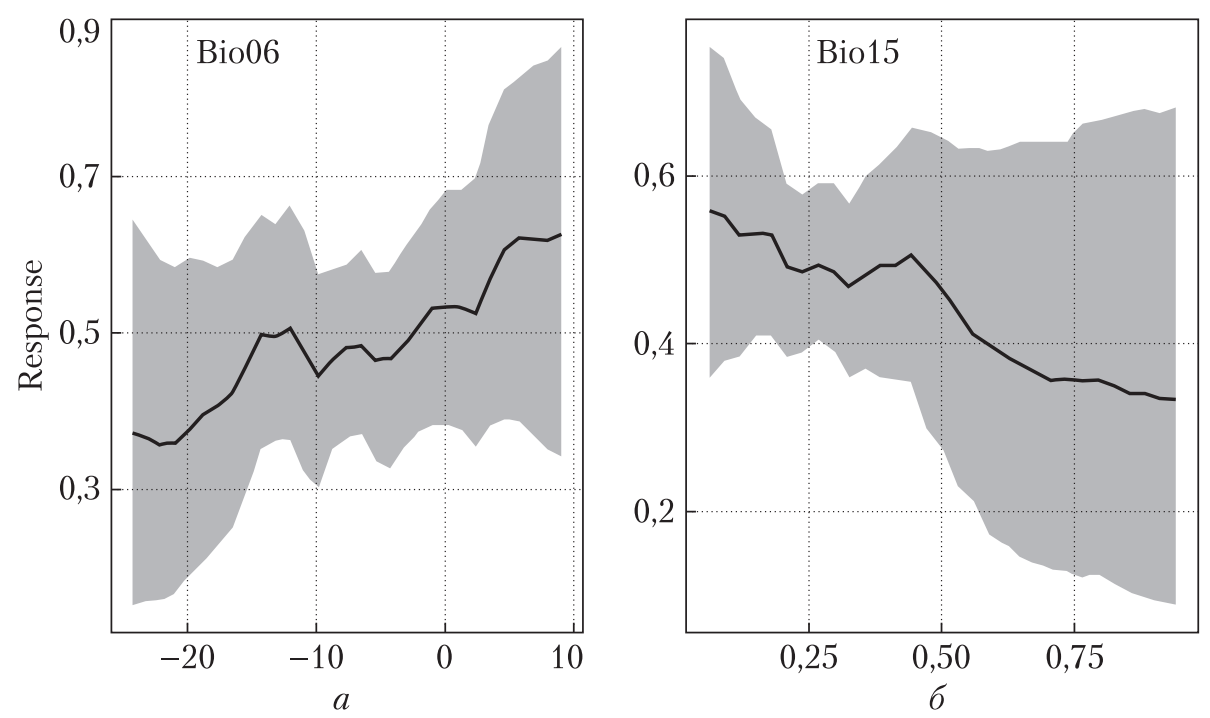

Puc. 2. Крива залежності мінімальної температури найхолоднішого тижня (Bio06), ${ }^{\circ} \mathrm{C}(a)$ і крива залежності сезонності опадів (Віо15), оцінена на підставі коефіцієнта варіації показника вологості (б); Response - придатність клімату; сірим кольором позначений 95 \% довірчий інтервал

Європи (Білорусі та РФ), то рівень придатності їх територій до спалахів коронавірусу є найменшим у Європі.

Майже вся територія України входить у зону з біокліматичними обставинами, сприятливими для коронавірусу та розвитку хвороби. 3 кліматичної перспективи в зону найменшого ризику потрапляє лише Херсонська область, де один з найнижчих показників кумулятивної кількості підтверджених захворювань. При цьому максимальний рівень придатності території України не перевищує 60 \%, що є середнім показником для Європи.

Користуючись пакетом “trafo" в програмному середовищі R (https://rdrr.io/github/ akreutzmann/trafo/), методом лінійної регресії встановлені зв'язки між кліматичною придатністю для SARS-CoV-2 в Європі та Україні і кумулятивним показником кількості підтверджених захворювань на 100 тис. населення. При цьому для отримання надійних результатів проведена діагностика виконання передумов щодо залишків, а саме припущення про нормальність розподілу, однорідності дисперсії залишків і відсутності в них кореляції, та зроблені тести на відповідність форми зв’язку. Результат діагностики показав, що не всі зазначені передумови виконуються, тому для виправлення ситуації до даних стосовно Європи в цілому була застосована Бокс-Кокс трансформація, а стосовно України замість початкових даних були використані їхні натуральні логарифми. У підсумку на матеріалах Європи виявлена високовірогідна позитивна кореляція $(r=0,22 ; n=226 ; p<0,001)$. Для України виявлено дещо більше значення коефіцієнта кореляції $(r=0,40 ; n=25 ; p<0,05)$ з меншим рівнем статистичної вірогідності (таблиця).

Алгоритм BART визначив вісім кліматичних предикторів, що є важливими для побудови моделі: Bio06 - мінімальна температура найхолоднішого тижня, Вio15 - сезонність опадів, Вio02 - середній добовий діапазон температур, Bio08 - середня температура найвологішої чверті, Bio05 - максимальна температура найтеплішого тижня, Bio13 - опади найвологішого тижня, Bio14 - опади найсухішого тижня та Bio07 - температурний річний 
діапазон. При цьому внесок температурних предикторів у побудову моделі становить приблизно 50 \%, факторів, пов'язаних з опадами, - 37,4 \%, внесок одного комбінованого предиктора (Bio08) - 12,6\%.

Крива залежності мінімальної температури найхолоднішого тижня (Bio06) (рис. 2, a) найкраще характеризує температурну залежність SARS-CoV-2. Там, де цей показник має низькі значення, кліматичні умови для вірусу є малопридатними. Починаючи з температури $-2{ }^{\circ} \mathrm{C}$ умови стають придатними певною мірою, а в температурному діапазоні від 6 до $10{ }^{\circ} \mathrm{C}$ придатність клімату є максимальною. Значення вологості краще за все характеризує крива залежності коронавірусу від показника сезонності опадів (Віо15) (рис. 2, б). Очевидно, що кращими для SARS-CoV-2 є території з рівномірним розподілом опадів протягом року, коли немає значного різкого чергування вологих та посушливих періодів.

Певним чином отримані результати перегукуються з даними, опублікованими раніше $[6,9,10]$. Наразі, за оцінками одних дослідників, ідеальна температура для поширення вірусу становить від 3 до $4{ }^{\circ} \mathrm{C}$ при рівні вологості у 20-80 \% [9], інші припускають, що найбільш комфортна температура для SARS-CoV-2 коливається в межах від -2 до $10{ }^{\circ} \mathrm{C}$ [10]. Аналіз умов у місцях, в яких виникли значні спалахи COVID-19, показав дуже схожий зимовий клімат. Первинно найбільш уражені регіони світу (Ухань, Північна Італія, Південна Корея, Сіетл і Іран) опинилися в межах одного температурного діапазону та рівня вологості, де середня зимова температура сягає від 5 до $11^{\circ} \mathrm{C}$, а рівень вологості - від 47 до 79 \% [6]. У кінцевому підсумку це означає, що пандемія COVID-19 може бути частково стримана із підвищенням температури та перепадами вологості [7].

Очевидно, що не тільки біокліматичні фактори, але й демографічні обставини, насамперед щільність населення, а також ефективність медико-організаційних заходів на державному рівні впливають на перебіг пандемії COVID-19. Однак аналіз біокліматичних факторів однозначно показує їх значущість у поширенні коронавірусної інфекції й утворенні спалахів хвороби. Більш того, певну комбінацію кліматичних факторів слід вважати базисом розвитку пандемії, адже умови навколишнього середовища об’єктивно за інших рівних умов впливають на те, де і коли хвороба з’явиться, а також модулюють її перебіг.

\section{ЦИТОВАНА ЛІТЕРАТУРА}

1. Межжерин С.В., Гарбар А.В., Гарбар Д.А., Жалай Е.И., Коршунова Е.Д., Морозов-Леонов С.Ю., Ростовская О.В., Соболенко Л. Ю., Васильева Л.А., Янович Л.Н. “Генетические ветра” Палеарктики: приложение концепции к территории Украины. Современные взгляды на эволюиию органического мира: Программа и тезисы докладов междунар. науч. конф. (Киев, 18-20 ноября 2009). Киев, 2009. С. 43.

2. Zaitchik B.F., Sweijd N., Shumake-Guillemot J., Morse A., Gordon C., Marty A., Trtanj J., Luterbacher J., Botai J., Behera S., Lu Y., Olwoch J., Takahashi K., Stowell J.D., Rodó X. A framework for research linking weather, climate and COVID-19. Nat. Commun. 2020. 11. 5730. https://doi.org/10.1038/s41467-02019546-7

3. Mecenas P., Bastos R.T.R.M., Vallinoto A.C.R., Normando D. Effects of temperature and humidity on the spread of COVID-19: A systematic review. PLoS ONE. 2020. 15, № 9. e0238339. https://doi.org/10.1371/ journal.pone.0238339

4. Pani S.K., Lin N.-H., RavindraBabu S. Association of COVID-19 pandemic with meteorological parameters over Singapore. Sci. Total Environ. 2020. 740. 140112. https://doi.org/10.1016/j.scitotenv.2020.140112

5. Islam A.R.M.T., Hasanuzzaman M., Shammi M., Salam R., Bodrud-Doza M., Rahman M.M., Mannan A., Huq S. Are meteorological factors enhancing COVID-19 transmission in Bangladesh? Novel findings from a 
compound Poisson generalized linear modeling approach. Environ. Sci. Pollut. Res. 2021. 28. P. 11245-11258. https://doi.org/10.1007/s11356-020-11273-2

6. Sajadi M.M., Habibzadeh P., Vintzileos A., Shokouhi S., Miralles-Wilhelm F., Amoroso A. Temperature, humidity, and latitude analysis to estimate potential spread and seasonality of coronavirus disease 2019 (COVID-19). JAMA Netz. Open. 2020. 3, № 6. e2011834. https://doi.org/10.1001/jamanetworkopen. 2020.11834

7. Paraskevis D., Kostaki E.G., Alygizakis N., Thomaidis N.S., Cartalis C., Tsiodras S., Dimopoulos M.A. A review of the impact of weather and climate variables to COVID-19: In the absence of public health measures high temperatures cannot probably mitigate outbreaks. Sci. Total Environ. 2020. 768. 144578. https:// doi.org/10.1016/j.scitotenv.2020.144578

8. Wu Y., Jing W., Liu J., Ma Q., Yuan J., Wang Y., Du M., Liu M. Effects of temperature and humidity on the daily new cases and new deaths of COVID-19 in 166 countries. Sci. Total Environ. 2020. 729. 139051. https:// doi.org/10.1016/j.scitotenv.2020.139051

9. Chin A.W.H., Chu J.T.S., Perera M.R.A., Hui K.P.Y., Yen H.-L., Chan M.C.W., Peiris M., Poon L.L.M. Stability of SARS-CoV-2 in different environmental conditions. medRxiv, 2020.03.15.20036673. https:// doi.org/10.1101/2020.03.15.20036673

10. Araújo M.B., Naimi B. Spread of SARS-CoV-2 Coronavirus likely to be constrained by climate. medRxiv, 2020.03.12.20034728. https://doi.org/10.1101/2020.03.12.20034728

11. Murray K.A.. Olivero J., Roche B., Tiedt S., Guégan J.-F. Pathogeography: leveraging the biogeography of human infectious diseases for global health management. Ecography. 2018. 41, № 9. P. 1411-1427. https:// doi.org/10.1111/ecog.03625

12. Conrad O., Bechtel B., Bock M., Dietrich H., Fischer E., Gerlitz L., Wehberg J., Wichmann V., Böhner J. System for Automated Geoscientific Analyses (SAGA) v. 2.1.4. Geosci. Model Dev. 2015. 8. P. 1991-2007. https://doi.org/10.5194/gmd-8-1991-2015

13. Carlson C.J. embarcadero: Species distribution modelling with Bayesian additive regression trees in R. Methods Ecol Evol. 2020. 11, № 7. P. 850-858. https://doi.org/10.1111/2041-210X.13389

14. Kriticos D.J., Webber B.L., Leriche A., Ota N., Macadam I., Bathols J., Scott J.K. CliMond: global highresolution historical and future scenario climate surfaces for bioclimatic modelling. Methods Ecol. Evol. 2012. 3, № 1. P. 53-64. https://doi.org/10.1111/j.2041-210X.2011.00134.x

15. Hammer Ø., Harper D.A.T., Ryan P.D. PAST: Paleontological statistics software package for education and data analysis. Palaeontol. Electron. 2001. 4, № 1. Art. 4.9 pp.

Надійшло до редакції 06.05.2021

\section{REFERENCES}

1. Mezhzherin, S. V., Garbar, A. V., Garbar, D. A., Korshunova, E. D., Morozov-Leonov, S. Yu., Rostovskaya, O. V., Sobolenko, L. Yu. , Vasilieva, L. A. \& Yanovich, L. N. (2009, November). "Genetic winds" of the Palaearctic: application of the concept to the territory of Ukraine. Program and abstracts of reports of the international scientific conference Modern views on the evolution of the organic world (p. 43), Kyiv.

2. Zaitchik, B. F., Sweijd, N., Shumake-Guillemot, J., Morse, A., Gordon, C., Marty, A., Trtanj, J., Luterbacher, J., Botai, J., Behera, S., Lu, Y., Olwoch, J., Takahashi, K., Stowell, J.D. \& Rodó, X. (2020). A framework for research linking weather, climate and COVID-19. Nat. Commun., 11, 5730. https://doi.org/10.1038/ s41467-020-19546-7

3. Mecenas, P., Bastos, R. T. R. M., Vallinoto, A. C. R. \& Normando, D. (2020). Effects of temperature and humidity on the spread of COVID-19: A systematic review. PLoS ONE, 15, No. 9, e0238339. https://doi. org/10.1371/journal.pone.0238339

4. Pani, S. K., Lin, N.-H. \& RavindraBabu, S. (2020). Association of COVID-19 pandemic with meteorological parameters over Singapore. Sci. Total Environ., 740,140112.https://doi.org/10.1016/j.scitotenv.2020.140112

5. Islam, A. R. M. T., Hasanuzzaman, M., Shammi, M., Salam, R., Bodrud-Doza, M., Rahman, M. M., Mannan, A. \& Huq, S. (2021). Are meteorological factors enhancing COVID-19 transmission in Bangladesh? Novel findings from a compound Poisson generalized linear modeling approach. Environ. Sci. Pollut. Res., 28, pp. 11245-11258. https://doi.org/10.1007/s11356-020-11273-2 
6. Sajadi, M. M., Habibzadeh, P., Vintzileos, A., Shokouhi. S., Miralles-Wilhelm, F. \& Amoroso, A. (2020). Temperature, humidity, and latitude analysis to estimate potential spread and seasonality of coronavirus disease 2019 (COVID-19). JAMA Netw. Open., 3, No. 6, e2011834. https://doi.org/10.1001/jamanetworkopen. 2020.11834

7. Paraskevis, D., Kostaki, E. G., Alygizakis, N., Thomaidis, N. S., Cartalis, C., Tsiodras, S. \& Dimopoulos, M. A. (2020). A review of the impact of weather and climate variables to COVID-19: In the absence of public health measures high temperatures cannot probably mitigate outbreaks. Sci.Total Environ., 768, 144578. https://doi.org/10.1016/j.scitotenv.2020.144578

8. Wu, Y., Jing, W., Liu, J., Ma, Q., Yuan, J., Wang, Y., Du, M. \& Liu, M. (2020). Effects of temperature and humidity on the daily new cases and new deaths of COVID-19 in 166 countries. Sci. Total Environ., 729, 139051. https://doi.org/10.1016/j.scitotenv.2020.139051

9. Chin, A. W. H., Chu, J. T. S., Perera, M. R. A., Hui, K. P. Y., Yen, H.-L., Chan, M. C. W., Peiris, M. \& Poon, L. L. M. (2020). Stability of SARS-CoV-2 in different environmental conditions. medRxiv, 2020.03.15.20036673. https://doi.org/10.1101/2020.03.15.20036673

10. Araújo, M. B. \& Naimi, B. (2020). Spread of SARS-CoV-2 Coronavirus likely to be constrained by climate. medRxiv, 2020.03.12.20034728. https://doi.org/10.1101/2020.03.12.20034728

11. Murray, K. A. Olivero, J., Roche, B., Tiedt, S. \& Guégan, J.-F. (2018). Pathogeography: leveraging the biogeography of human infectious diseases for global health management. Ecography, 41, No. 9, pp. 14111427. https://doi.org/10.1111/ecog.03625

12. Conrad, O., Bechtel, B., Bock, M., Dietrich, H., Fischer, E., Gerlitz, L., Wehberg, J., Wichmann, V. \& Böhner, J. (2015). System for Automated Geoscientific Analyses (SAGA) v. 2.1.4. Geosci. Model Dev., 8, pp. 19912007. https://doi.org/10.5194/gmd-8-1991-2015

13. Carlson, C. J. (2020). embarcadero: Species distribution modelling with Bayesian additive regression trees in R. Methods Ecol. Evol., 11, No. 7, pp. 850-858. https://doi.org/10.1111/2041-210X.13389

14. Kriticos, D. J., Webber, B. L., Leriche, A., Ota, N., Macadam, I., Bathols, J. \& Scott, J. K. (2012). CliMond: global high-resolution historical and future scenario climate surfaces for bioclimatic modelling. Methods Ecol. Evol., 3, No. 1, pp. 53-64. https://doi.org/10.1111/j.2041-210X.2011.00134.x

15. Hammer, Ø., Harper, D. A. T. \& Ryan, P. D. (2001). PAST: Paleontological statistics software package for education and data analysis. Palaeontol. Electron., 4, No. 1, Art. 4, 9 pp.

Received 06.05.2021

\section{S.V. Mezhzherin \\ I.I. Kozynenko \\ V.M. Tytar, https://orcid.org/0000-0002-0864-2548}

I.I. Schmalhuasen Institute of Zoology of the NAS of Ukraine, Kyiv

E-mail: s.mezhzherin@gmail.com

BIOCLIMATIC FACTORS AND THE COURSE

OF THE COVID-19 PANDEMIC IN EUROPE:

THE PLACE OF UKRAINE

The dependence of the COVID-19 pandemic on 8 of the 35 analyzed bioclimatic factors has been proven in Europe. Their combination objectively determines the spatial basis of the pandemic. The optimal conditions for the development of the pandemic are determined by two key parameters: the minimum temperature of the coldest week of the year in the interval from 6 to $10{ }^{\circ} \mathrm{C}$ and a constant level of seasonal humidity. The most suitable for the development of the pandemic are the territories of the Western Europe (indicators of fitness from 60 to $80 \%$ ). Central and Northern Europe are characterized by an average level of suitability (50-60 \%). The lowest level in the Eastern Europe is about $50 \%$. The territory of Ukraine belongs to the average suitable. Therefore, given the low, as for most European countries, population density, any excessive manifestations of the pandemic should be explained only by the low efficiency of medical and organizational measures nationwide.

Keywords: COVID-19, climate, ecological niche modeling, Europe, Ukraine. 